\title{
Young creators in open spaces: digital ethnography ${ }^{1}$
}

\author{
Sara Cortés \\ sara.cortesg@uah.es \\ María Ruth García-Pernía \\ mruth.garcia@uah.es \\ Julián de la Fuente \\ julian.fuente@uah.es \\ Rut Martínez-Borda \\ rut.martinez@uah.es \\ Pilar Lacasa \\ p.lacasa@uah.es \\ University of Alcalá, Spain
}

\begin{abstract}
The goal of this paper is to analyze the creative processes undertaken in a community of teenagers participating in entertainment workshops designed to develop digital literacies. The main goal is to outline support strategies to generate digital literacy among young people who participate in social networks. We adopt an ethnographic and action research approach to explore the creative process undertaken in an informal educational environment. Methodologically, narrative reconstructions are combined with an analytical approach. The results obtained were three-fold: 1) Specific audiovisual content depends on the material and social context in which it was generated. 2) When multimodal discourses are used, their use is conditioned by the mobile applications that young people use and the need to integrate different modes. 3) The conversations and practices that take place in the workshop focus young people's attention on creative and critical practices when using social networks such as Vine and Instagram.
\end{abstract}

\section{Keywords}

Preadolescents; teenagers; digital literacy; creativity; multimodal discourse; crosssetting.

1 Permissions: The participants names have been changed for keeping total anonymity. Families explicitly agreeing, by signature, and give signed permissions for their participation in the study and the images publication.

Acknowledgements: Thank you so much to the children involved in this study, for her participation and cooperation during the research, and to their families.

Founding: This work was supported by the Ministry of Economy and Competitiveness (Spain) EDU201234624, and Telefónica (Spain) 


\section{Introduction}

Today, the Internet and new technologies are educational instruments that mediate specific forms of discourse. These tools have given rise to a series of changes in the parameters of human learning, i.e., in what, when, how, where, by whom and with whom learning takes place, and also in the reasons why people learn. We are seeing the emergence of a learning ecosystem which is characterized, among other features, by the multiplicity of contexts, opportunities and resources for learning, as well as by a configuration of individual learning pathways. This study explores scenarios that contribute to the development of digital literacy and creative thinking, supported by multimodal discourses. The objectives are as follows:

1. To define support strategies that contribute to the development of digital literacy, based on participation in social networks.

2. To analyze the multimodal discourses that mediate young people's creative practices, looking at the meaning construction processes in specific social and cultural contexts.

3. To examine creative processes, from the creator's perspective, as generators of specific audiovisual content which is uploaded to social networks, mediated by material objects in the open spaces of a community art center.

These pages form part of a broader study that analyzes the activities of young people when they operate mobile devices and participate in social networks in informal educational settings. The study is divided into three parts. The first part outlines the theoretical model adopted, which seeks to generate personalized learning situations (Coll, 2015) in relation to digital literacy (Gee, 2013; Penuel \& O'Connor, 2018). We look at the role of creativity as a process which is not only personal but also social (Jones, 2012). In the second section, the methodological approach is supported by ethnography (Boellstorff, 2012) and action research (Kemmis, McTaggart \& Nixon, 2014). This is the framework which provides the context for participant observation by the researchers at the workshops created to develop young people's digital literacy. Finally, in the third section, the results obtained are presented, in relation to the objectives outlined. We will show the creation process of multimodal audiovisual content - which is published on social networks - carried out by the participants in the workshop.

\section{Theoretical background}

The presence of new technologies in people's lives offers a range of communication possibilities and transforms the way that information and knowledge are received, exchanged and disseminated. New communicative and multimedia environments require people to learn to handle new forms of expression, based not only on oral and written language, but also on audiovisual codes that use images and sound. There is a need to acquire new skills related to the mastery of multiple discourses, through personalized learning situations, to allow people to become creators. Figure 1 shows the concepts that shape our theoretical model and the authors that serve as a starting point for our study. 


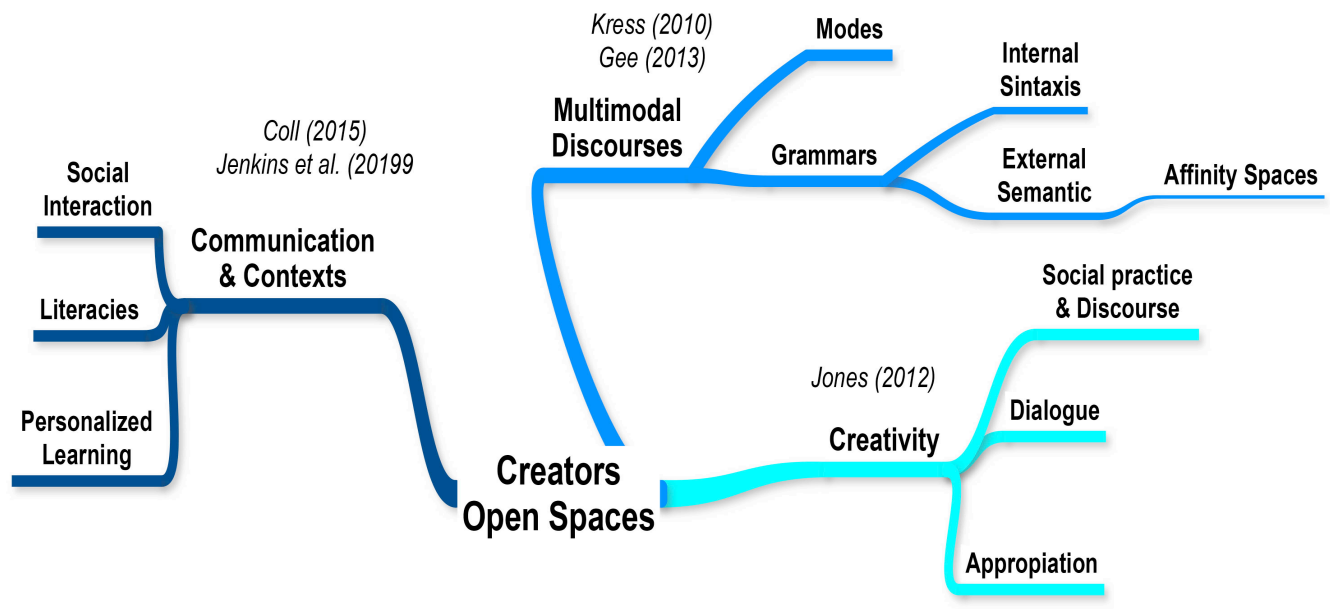

Figure 1. Seeking an integrative theoretical model

\section{a. Educational contexts, communication and literacy}

When discussing formal or informal educational contexts where we seek personalized learning mediated by digital technology and the discourse that is generated from it, we must look beyond the walls of the classroom. We will now look at some of the dimensions of these educational contexts. Firstly, they are related to material situations of social exchange where texts are constructed, consumed, exchanged and appropriated. Secondly, technology that was analogue years ago and is now digital has altered how we experience space and time, creating levels of online and offline life that require people to be digitally literate. These contexts can also be conducive to forms of personalized learning, understood as a set of actions - educational strategies - which facilitate learning and have a meaning and a personal value for learners (Coll, 2015; Guitart et al., 2017).

We associate communicative exchanges with discourse, as a mediating instrument that "should be studied not only as form, meaning and mental process, but also as complex structures, interaction hierarchies and social practices, as well as their functions in context, society and culture" (van-Dijk, 1997, p.6). That is, discourse has a dimension that goes far beyond individuals or the fact of being a mediator in interpersonal communication; it has a social dimension that is even related to aesthetic and cultural values. Participating in the culture of a certain society implies sharing meanings. From this perspective, digital texts are understood as symbolic expressions that emerge from dialogue and processes of intersubjectivity. People not only receive information, they also have to interpret what others have generated.

For these communicative exchanges mediated by digital technology to be effective, we need people to be able to handle certain instruments. We can speak, then, of media literacy, which was defined by David Buckingham as "the knowledge, skills and competencies required to use and interpret the media" (Buckingham, 2004, p.71). This means that media literate people have the ability to read, as well as write, through various different media, with a critical approach. This concept was quickly adopted by the educational community. We can infer, then, that the current debate on the subject reveals a need to define digital literacy, which is understood as "The skill set where auditory, visual and digital literacy are superimposed. Includes the ability to understand the power of images and sounds, recognize and use that power, manipulate and transform digital media, distribute them in a widespread 
form" (Jenkins, et al., 2009, p 271). Most recently, (Jenkins, Itō \& Boyd, 2015) talked about how literate people are not only able to handle instruments, but also to build knowledge.

Let us now look at the personalization of learning, understood as something "that goes far beyond the will to adjust the educational action to the characteristics and needs of the learner. The ultimate purpose of personalization is that the learner gives a personal meaning to what they are learning" (Coll, 2015, p.6). We are interested in highlighting the circumstances that surround this learning, especially the support strategies that can help generate it (Guitart et al., 2017). We can examine three dimensions of the context that contribute to generating this type of learning. Firstly, we must consider the participants, taking into account that people have social roles which are closely related to their discourse, the meaning of which must be interpreted according to those roles. Secondly, the scenario defined by physical and virtual objects that located the participants within local and global worlds; today, the knowledge which education seeks to generate must be considered as part of this broader context. Thirdly, the activities and practices of people, as the interpreters of texts which mediate communication.

We can therefore say that in educational contexts mediated by digital technology, there can be multiple forms of communication that can foster personalized learning. We are faced with environments where people share meanings and the discourse generated is studied as a mediating element that has an important social dimension.

\section{b. Multimodal discourses}

We shall look here at how multimodal discourses can be understood. We speak of discourse because we refer to the way that language is used in specific communicative situations, from which meaning is generated. We refer to the idea of multimodality because multiple expressive resources are combined, for example, words, sounds, gestures and images. These discourses, as the contextualized manifestations of oral and written language, can be better understood by exploring the grammar based on which they are configured, especially the syntax and semantics. These two dimensions will have to be taken into account in educational settings aimed at facilitating the development of digital literacy which is clearly associated with the development of this multimodal discourse.

If we look at the syntactic dimension of multimodal discourses, it is noteworthy that they combine signs forming systems, wholes, in which some have meaning in relation to others. Just as in oral and written language, where words are integrated into sentences, something similar happens with other expressive forms. This idea places the focus on the different configurations present in communication environments which combine various different expressive resources, including image, gesture, sight, sound, posture, music and writing. Each of these is considered to be a mode, but what is relevant is that they do not appear in isolation; they interact and construct meaning systems (Jewitt, 2008). In this vein, Gee (2003) refers to the principles and patterns that allow for connections between the elements of a discourse that relies on digital technology, which he calls internal grammars. In an educational situation, it is important to seek coherence, as combining the modes randomly cannot achieve the utmost expressiveness.

In addition, the combinations of modes to which we refer above generate meanings, hence their semantic dimension, always bearing in mind that meanings are intertwined with culture. That is to say, images, sounds, gestures and any type of sign are relevant because 
people attribute a meaning to them (Kress, 2010; Kress \& Van Leeuwen, 2001). Gee (2003) also refers to semiotic domains and considers them external grammars, referring to the fact that any content can be examined in relation to a set of social practices. This concept of semantic domain is subsequently extended with the affinity space (Gee, 2013) which, as a notion, is especially useful to understand how meaning is constructed in certain areas and communities.

In short, education that aims to foster personalized learning, and whose content and practices are relevant and meaningful for teachers and learners alike, must take into account meaning construction processes supported by the use of multimodal discourses, which are, in turn, a platform for creativity, as discussed below.

\section{c. Creativity as personal and social process}

Traditionally, creativity has been understood as a quality attributed to artists, great scientists, people who had acquired broad social recognition; it could be considered "Creativity" with a capital letter, to a certain extent. Today, it is accepted that creativity is present in everyday life (Jones, 2012). Things which are classed as creative involve both people and productions, and also take into account the environment in which they emerge. These ideas were suggested by Chomsky: "Creativity is the core of language itself, its essential property, which gives it the means to indefinitely express many thoughts and to react appropriately in an infinite set of situations" (Chomsky, 1965, P. 3).

Expanding on this view, Van-Dijk (2014) makes several precisions, relating creativity to the concept of appropriation, understood as the way one uses the resources of others to create one's own productions. It has a range of salient features. Firstly, it is the capacity which, associated with the construction of meaning, allows us to recognize certain patterns in experiences in the world, and to go beyond them. Secondly, creative processes are associated to discourse in use, generated from specific practices such as the construction of knowledge, and even certain forms of power. Thirdly, creativity is not related only to language, but to the people who use it. It is a process of adaptation and transformation when faced with new circumstances.

Transcending the notion of discourse, other authors have associated creativity with ideas such as freedom and overcoming limitations (Negus \& Pickering, 2004, Thurlow, 2012). In any case, it is also limited by convention. We can understand better these features by examining two ideas. Firstly, this work seeks to explore creativity in communities and through productions that do not represent culture with a capital " $C$ ". Secondly, creation involves design and transformation, which is not possible without reference to rules, instruments, codes and procedures.

In short, creativity explored in educational contexts emerges from a tension between the fixed and the mobile, limitations and freedom, invention and innovation, strictness and defiance, orthodoxy and heterodoxy, grammar and poetry. It is marked by the immediate social and cultural context, together with its structures, rules and codes. Discourse and culture are open systems and, in this framework, creativity, imagination and play are essential. 


\section{Methodology}

\section{a. Methodological overview}

The use of qualitative approaches has always been present in media studies (Hartley, 2012). In this work, we combine narrative strategies and conceptual analysis as a framework for research (Lacasa, Martinez-Borda \& Mendez, 2013). It is a framework that is especially useful for approaching data that stems from user participation in face-to-face contexts and in social networks. In this study, we combine several methodological approaches, which will allow us to understand how human activities acquire meaning in the social, cultural and historical contexts in which they arise (Denzin \& Lincoln, 2011).

Action research allows for the adoption of a critical paradigm aimed at reflecting on our activity as researchers (Hammond \& Wellington, 2013). It is an iterative process of planning, observation and abstraction around a specific practice. In addition, in this study we understand ethnography as a way to approach the culture of specific groups - in this case young Madrid-based adolescents in leisure situations - which places the observer in the world, immersed in processes of meaning construction. The study also adopts the framework of discourse analysis (Gee, 2014), combined with visual methodologies (Margolis \& Pauwels, 2011; Stanczak, 2007; Pink, 2012).

\section{b. Context, participants and data collection}

\section{The workshop}

The object of our study are the practices that children undertake in workshops organized by the research team with the support of community institutions, specifically the Matadero in Madrid. The research takes place in an informal educational environment and the young people attend for leisure purposes. There were 11 sessions with boys and girls of between 8 and 14 years old. The maximum number of attendees was 28 .

The sessions took place on Sunday mornings, for two and a half hours. There was an interdisciplinary research team, including senior and junior researchers, and students from the degree in Audiovisual Communication. The team comprised between 12 and 15 people. The tasks were programmed previously by the research team and negotiated with the participants during the first part of the workshop. They were aimed at promoting the development of digital literacy, in relation to creative processes that relied on the use of multimodal discourses. Because children of that age tend to use, in many cases, social networks such as Vine or Instagram, situations of communication mediated by digital instruments were created that allowed access to and publication on these networks. We had 14 Mini iPads, with Internet connection through 4G technology. In addition, the researchers used a Mac laptop, which allowed for the projection onto a large screen of the productions on the iPads, the material contributed by the research team and the publications on social networks which were generated or examined during the workshop, all using Apple TV technology.

As we have in previous works (Lacasa, de-la-Fuente \& Martín-Garrido, 2016), we rely on an educational process which seeks to combine reflection, dialogue and creation. Therefore, the workshop and each of its sessions was structured around four processes: dialogue, action, reflection and publication. These processes are outlined in Figure 2. 


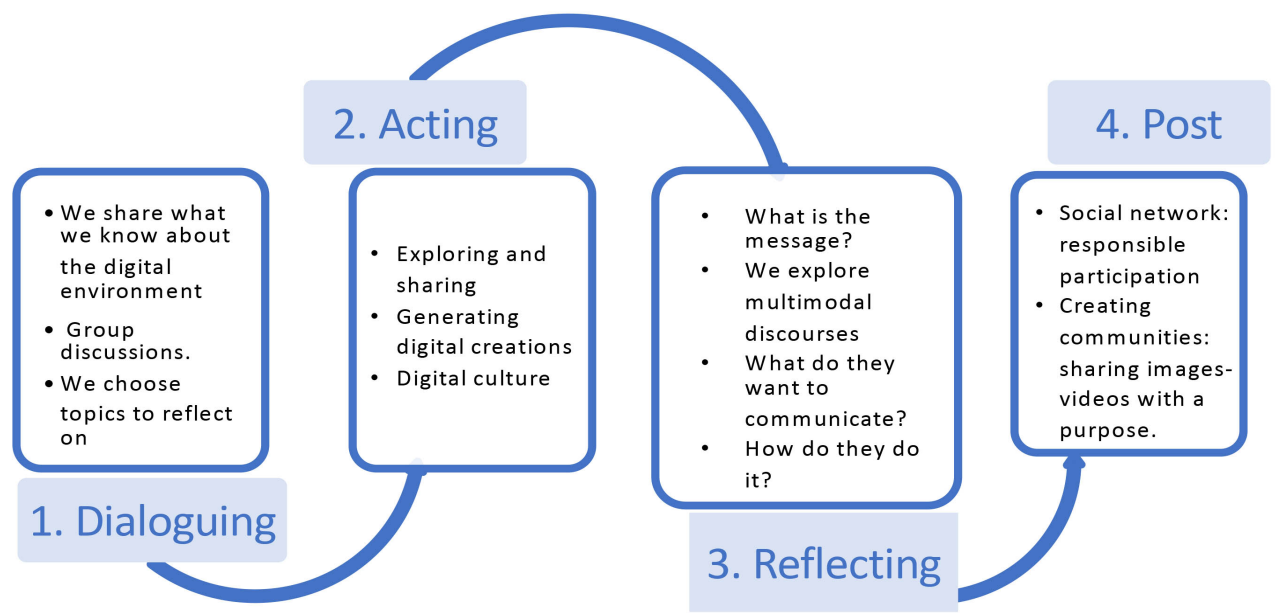

Figure 2. Phases and development of the workshop sessions

Considering people as recipients and creators of messages, as reflected in Figure 2, the workshop combined activities and tasks that allow for gradual, continuous progress in the use of multimodal discourses. These discourses mediate the creative processes, allowing the participants to become aware of and control their forms of expression. Starting from a dialogue in a large group, where the goal of the workshop was presented and the communicative situations in which children practiced and acted - using social networks, with the help of researchers - were shown. All of this facilitated collective and interpersonal reflection. Also, the productions generated were published and shared through Vine and Instagram. We wanted participants to master different expressive modes and consciously use multimodal discourses. Situations of large and small group were combined in a flexible manner.

\section{Data collection and analysis}

All data was collected using qualitative research techniques. All sessions were recorded using video and audio systems. The use of professional cameras by audiovisual communication students was combined with the use of mobile phones; the researchers used these devices to record specific situations in which they participated and which were of particular interest. This audiovisual data was extended with summaries, compiled each day by each person present at the workshops, who contributed their own interpretation of the sessions. The images shown below allow us to observe how the influence of space and instruments contributed to creating a personalized learning context (Coll, 2015). The three photographs in Image 1 show various scenarios from the workshops.
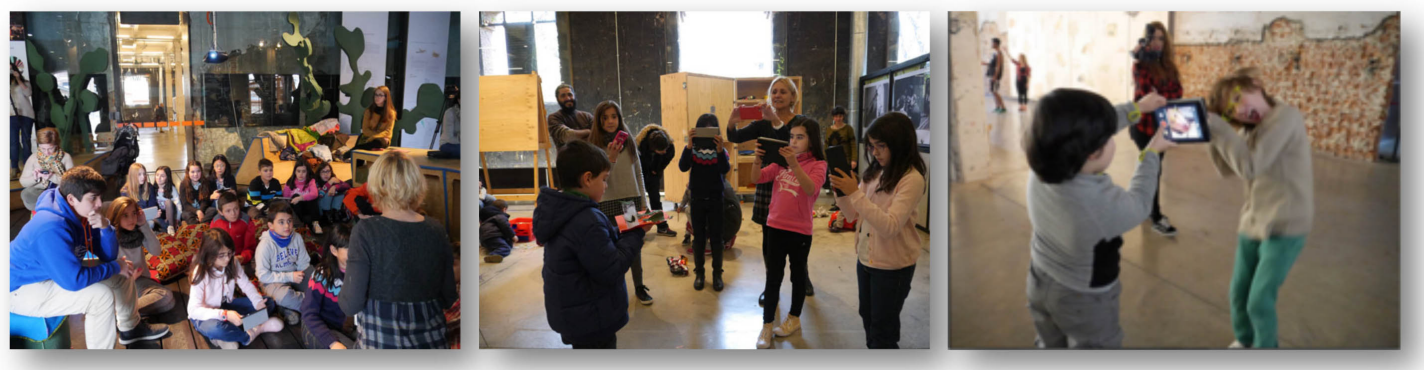

Image 1. The workshop in the facilities at Matadero (Madrid) 
The first photograph shows a social situation mediated by dialogue in close proximity in a large group (Van-Dijk, 1997). The young people and adults share a common goal: to establish processes of civic and community participation, supported by scenarios where people interact with each other in real and digital environments, building and reconstructing different cultural manifestations, especially those related to visual art.

The second image shows how the Matadero facilities became a source of support for the workshop, as its spaces became the protagonists of the children's stories (Lacasa et al., 2016). After the dialogue, small working groups were created that explored the main cultural spaces of the Matadero, including the Casa del Lector, the Central de Diseño and Intermediae. The young people gradually opened up to their surroundings them, but at the same time, they shared their impressions, their thoughts and their observations through an online social network. Their practices were located in these two scenarios, real and virtual, defined culturally in both cases.

The third photograph shows the connection between the real and virtual scenarios in which people relate to each other (Boellstorff, 2012). Sometimes face to face, sometimes through a mobile device that puts them in contact with audiences, which may be more or less distant. Undoubtedly, the relationships in the physical world between people who participated in the workshop, both young people and researchers, contributed to generating a certain vision, which was projected in photographs and videos. The space where the workshop took place became a learning environment focused on how to use digital tools to connect one's experiences in different space-time environments (Buckingham, 2004).

Table 1 includes video recordings and photographs collected during the sessions both by the researchers and by the children. As we can see, there is a difference between the research team's productions and those of the children. It should be noted that the fact that the recordings were made in a very open space created research environments which are very different from those that occur in the classroom. For example, participants moved through different spaces, inside and outside the building. They visited a range of areas, including exhibitions, and sat anywhere they liked, in large or small groups, to perform and review the tasks set.

\begin{tabular}{|c|c|c|c|c|c|c|c|}
\hline Session & Topic & Participants & $\begin{array}{l}\text { Team } \\
\text { photos }\end{array}$ & $\begin{array}{l}\text { Children } \\
\text { photos }\end{array}$ & $\begin{array}{l}\text { Children } \\
\text { videos }\end{array}$ & Team clips & $\begin{array}{l}\text { Team } \\
\text { recordings }\end{array}$ \\
\hline 0 & Pilot & 5 & 125 & 91 & & & \\
\hline 1 & $\begin{array}{l}\text { Actors in } \\
\text { social } \\
\text { networks }\end{array}$ & 14 & 347 & 676 & 12 & 240 & $6: 49: 28: 20$ \\
\hline 2 & $\begin{array}{l}\text { Actors in real } \\
\text { 8 virtual life }\end{array}$ & 14 & 466 & 1133 & 33 & 168 & $6: 31: 12: 12$ \\
\hline 3 & $\begin{array}{l}\text { We work } \\
\text { with apps }\end{array}$ & 14 & 570 & 1427 & 16 & 54 & $5: 36: 07: 05$ \\
\hline 485 & $\begin{array}{l}\text { Audiovisual } \\
\text { discourses }\end{array}$ & 22 & & 664 & 58 & & \\
\hline 4 & & & 614 & & & 57 & $6: 12: 13: 23$ \\
\hline 5 & & & 390 & & & 42 & $6: 03: 22: 02$ \\
\hline 6 & $\begin{array}{l}\text { Professionals } \\
\text { as models? }\end{array}$ & 14 & 306 & 28 & 77 & 45 & $6: 30: 19: 05$ \\
\hline 7 & $\begin{array}{l}\text { Limitations } \\
\text { of the apps }\end{array}$ & 10 & 296 & 325 & 149 & 32 & $5: 05: 58: 62$ \\
\hline 8 & Sound & 23 & 185 & 52 & 161 & 72 & $6: 38: 09: 14$ \\
\hline 9 & $\begin{array}{l}\text { Storytelling } \\
\text { with Adobe } \\
\text { Voice }\end{array}$ & 16 & 278 & 643 & 61 & 20 & $4: 26: 14: 05$ \\
\hline 10 & $\begin{array}{l}\text { Multimodal } \\
\text { stories }\end{array}$ & 23 & 425 & 991 & 49 & 25 & $4: 10: 16: 01$ \\
\hline Total & & 155 & 4002 & 6030 & 616 & 755 & $58: 0: 03: 15$ \\
\hline
\end{tabular}

Table 1. Data collected in the workshop 
As indicated, our research combined narrative and conceptual approaches (Lacasa et al., 2013), supported by qualitative software for qualitative analysis (NVivo) and professional tools for organization, edition and audiovisual production (Final Cut Pro). To explore Instagram productions, we used web access through Iconsquare. We will show the results of the work below, exploring the workshop's development process, analyzing the events of the workshop both in large and small groups, and examining the productions created by the children and young people during the sessions.

\section{Results}

The results of this experience show the work carried out during the 11 workshop sessions that took place in the sociocultural space of the Matadero in Madrid, where both the space itself and individuals and technologies present gave rise to various different multimodal discourses and new ways of communicating and creating. Social networks, our starting point, became a dynamic context and allowed for the creation of affinity spaces in which children participated with research team. We are looking here at personalized learning which is generated among people beyond social media. A process through which to share ideas, visions and knowledge, and to learn together about the value of social media. The dimensions on which we focused our attention are summarized in Figure 3.

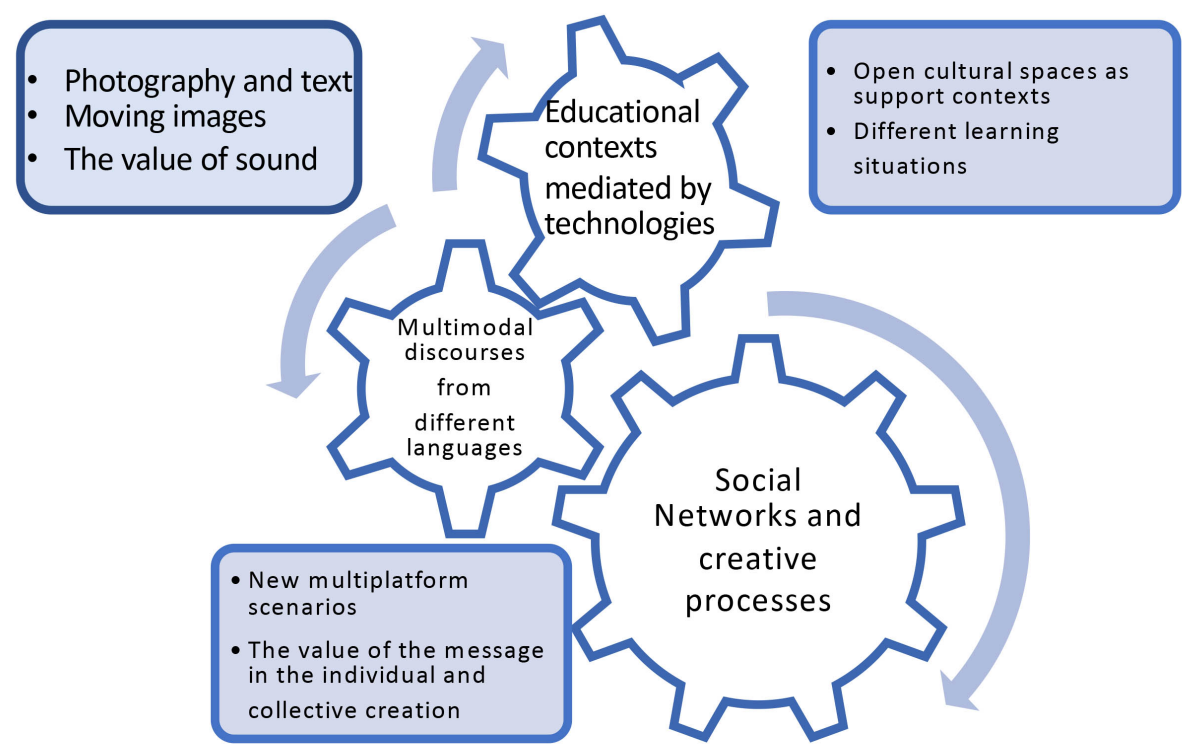

Figure 3. Dimensions of research analysis

If we observe Figure 3 closely, we can identify three dimensions. Firstly, educational contexts mediated by technologies, where we will focus on analyzing the space in which the workshop took place and the key elements in the literacy process, both instruments and people. Secondly, multimodal discourses, which we will explore through examples of the productions created by young people, to show how they use photography, video and sound. Finally, we will analyze the social networks and creative processes that form the central axis of the workshop, through individual creation processes. 


\section{a. Educational contexts mediated by technologies}

Digital literacy from shared spaces

In the workshop, spaces were created where young people could look more deeply at the meaning of their productions, interacting with people who showed different levels of knowledge and practice in relation to the tasks to be performed. It was necessary to generate environments that facilitated dialogue through debate, allowing participants to verbalize their own experiences, references and usual practices. The aim was to provoke a process of awareness raising, both individually and at the group level, of the multimodal discourses used (Jewitt, 2008; Kress, 2010). Researchers sought to have each participant set a series of goals and, above all, to share their experiences with the rest of the group. The following is an example:
Transcript 1. LARGE GROUP SESSION. 20150315
Researcher: Have you ever made a video or not?
All: Yes.
$R$ : How do you make the videos?
$P$ : With my parents' mobiles
$R$ : And then what do you do with the photos?
$P^{\prime}$ : I save them on the mobile
$P^{\prime \prime}:$ I send them to WhatsApp
$R$ : That's a social network

This fragment shows us how the participants' previous experience is usually limited to taking photos or videos with mobile phones or household equipment belonging to their parents. What this means is that the majority of them had restrictions in place in terms of the control of these tools and the contents they created through them. Many children were unaware of the existence of social networks and how they can be used to create and share content. Therefore, as adults who support learning, we must focus on explaining, in depth, how to use the main photo and video tools offered by social networks. Whilst the younger participants found it difficult to understand what social networks are, as for them the Internet is something that allows them to watch videos, access YouTube or listen to music, the older participants wanted new knowledge, more in line with their age and personal experience.
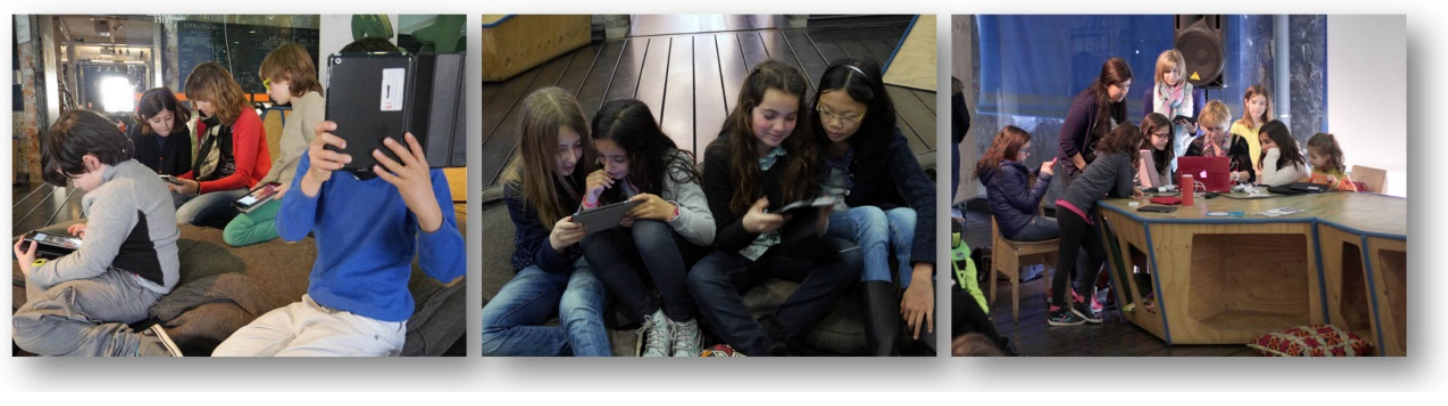

Image2. Working in small groups, personalized learning

The photographs in Image 2 show us how working in small groups or in pairs, interacting in some cases with researchers and in others between peers, generated a close learning experience which facilitated dialogue and personal conversations.

Participants and experts involved in the progress of the workshops

Whilst the workshops are educational, there is no doubt that they take place in an informal context. It is worth observing one situation that is particularly relevant in this regard: the 
role played by participants who already have previous experience in the workshop, and who help both the researchers and the other participants. At one point, we introduced the figure of "experts" (Jones, 2012). Their presence helped promote personalized, collaborative learning. A situation representing this relationship is shown in Image 3.

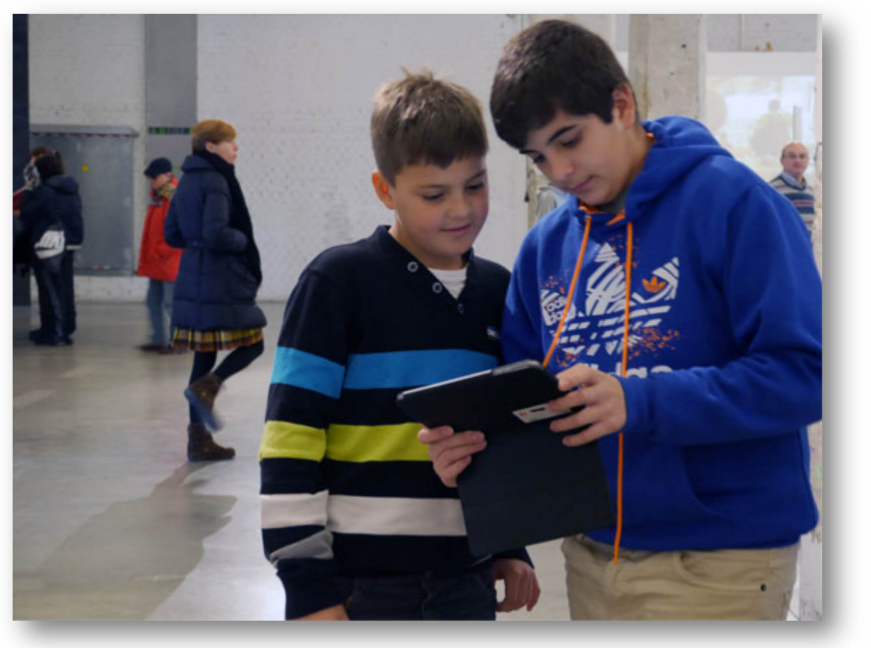

Image 3. Expert helps another participant. 20150118

We shall look now at a dialogue that will help us understand the relationship between the researchers, the children who acted as experts and the other participants.

Transcript 2. RESEARCHERS, EXPERTS AND PARTICIPANTS. 20150315

Researcher: how do you start recording?

Expert: First you focus.

R: What do mean by focus? On what you want to express, or on what is in front of you? E: On what is in front of me.

R: First you think of what you have in front of you, and then you think of what you can express with that, is that correct?

E: That's right. And then, I think of the light.

R: Why the light?

E: Because I like it to be light, without too many shadows.

$R$ : Do you think of sound too?

E: Yes, but less.

We can observe that while the researcher encourages the creation of common goals, the expert child helps with more technical questions, and the novice generates ideas to achieve the objectives proposed. The roles of the novice, expert and researcher fit well into the workshop. Only when each participant assumes the proper function of their experience does a fluid learning activity occur.

\section{b. Multimodal discourses from different languages}

Generating scenarios where digital productions are created and interpreted through mobile applications and social networks related to photography and video requires careful session planning (Kenmmis et al., 2014). The idea was to explore the use of different tools and languages for content creation. We will use examples to illustrate this. Situations such as those in image 4 were common in the workshop, where the participants combined images, sounds, voices and even gestures (Kress, 2010). 

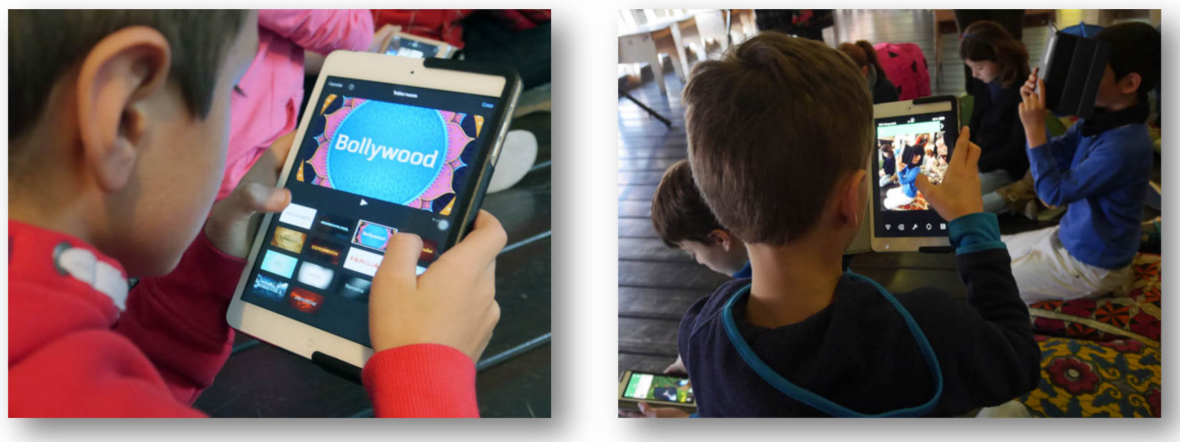

Image 4. Using multimodal discourses mediated by digital technology. 20150118

Video from photography

An analysis of the sessions showed us that there is no single strategy to make young people aware of the power of images. We used a multimodal approach (Kress, 2010), so diverse expressive resources were combined. One example of this multimodality is found in a video made by a 12-year-old girl. It is a production made with Flipagram, an app included on the iPad. It combines images and gives a sense of movement, although it is based on the use of photographs. The ability to add music also contributes to the effect.

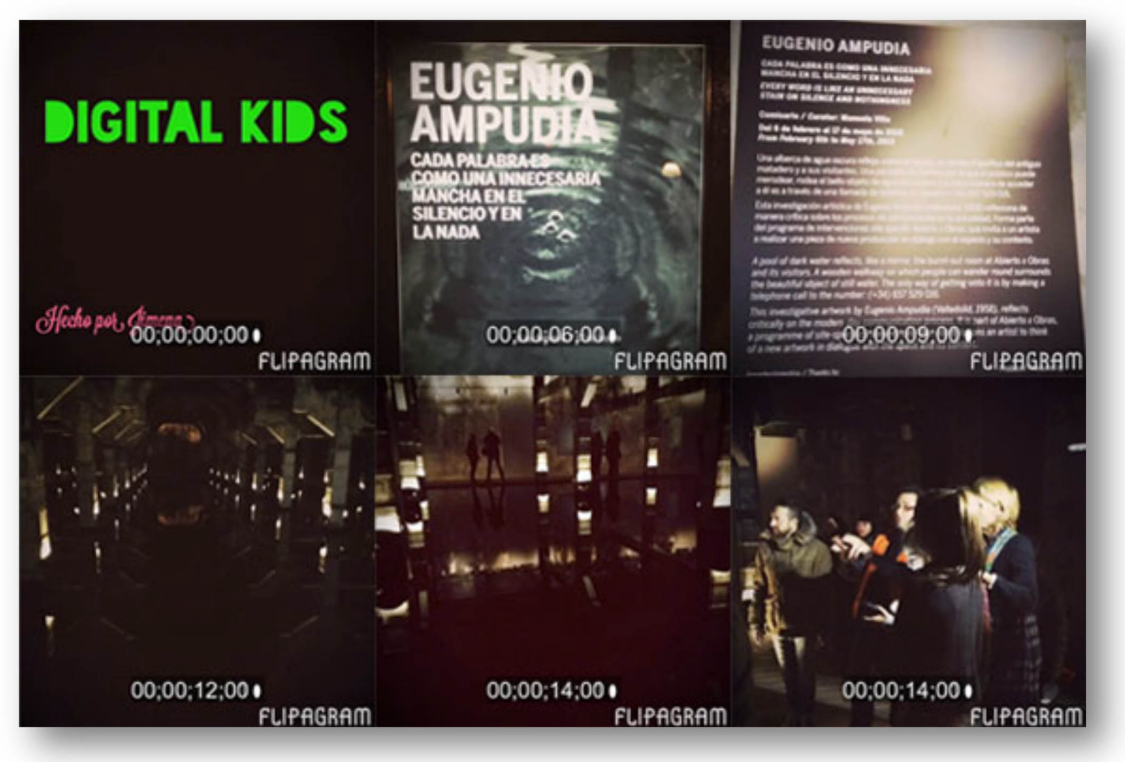

Image 5. From photography to video. 20150118

Image 5 shows fragments of the video, in which moving and static images are combined. It is made in a completely dark room, where it was very difficult to record using the iPad camera. Several participants tried to do so during that session, and the result was that their productions were poorly lit or out of focus. This girl, on the other hand, manages to make a video about the exhibition based on photographs which are sharp and acceptably well-lit, in keeping with the ambient light. The mastery of audiovisual language, therefore, does not depend so much on the technical management of digital equipment, in this case an iPad, but more on using criteria and determining the relevance of using one expressive resource or another (Jewitt, 2008). 


\section{Moving images}

An analysis of the young people's audiovisual productions revealed that photography did not allow them to fully represent in their messages the actions related to the socio-cultural context in which they found themselves, as we already anticipated (Kress \& Van Leeuwen, 2001). Their productions on Vine showed what was around them, such as the exhibitions they visited and the workshop environment. Their creations focused on topics such as dance, theater, action and movements. An example appears in Image 6.

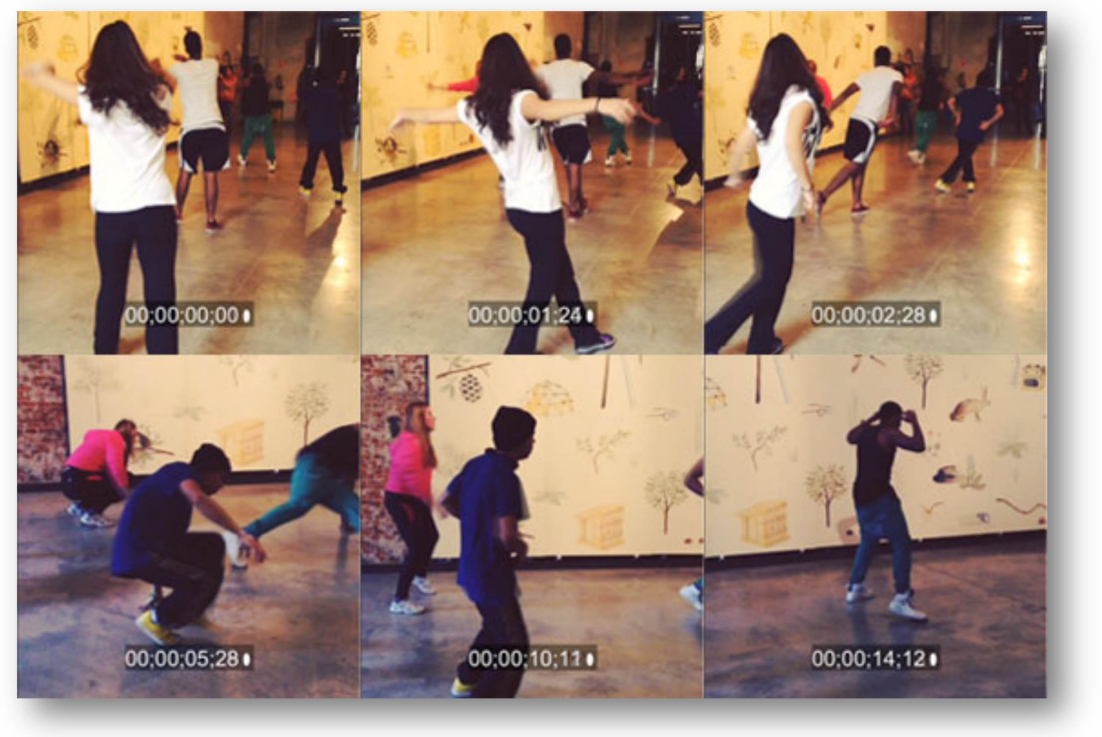

Image 6. Recording movement. 20150118

Image 6 reproduces the video made by a nine-year-old girl, in which the movement of a group of dancers is perfectly captured. It is striking that she does not even bother to record the dancers from the front, but that it is enough to take two shots from behind and from the side to show their movements. Above all, it highlights the use of a perspective which, by placing the figures diagonally, manages to transmit the maximum dynamism from a static position. We can say that they transmit the movement by changing the perspective of the iPad.

The value of sound

Sound tends to be overlooked in productions by young people. For example, the videos usually leave the natural background sound, or include music that corresponds to personal taste, to an interest in the song itself, rather than to its relation with the sound. This is what they upload to social networks because often there is no time for anything more. Sometimes, when the recording is edited, music is added which is attractive to the creator, without thinking about the images it accompanies.

There is no doubt, in any case, that sound opens up new channels of communication when combined with images. Therefore, in our ongoing progress and evolution in each of the sessions, there came a moment when we perceived the need to work on sound and its importance as an instrument of communication when combined in a coherent way with images, be they static or moving. Below is an example taken from the use of sound by a twelve-year-old boy and girl through a loop recording. The video shows a person visiting an exhibition, to which they add diverse sounds and musical effects conveying suspense (Image 7). 


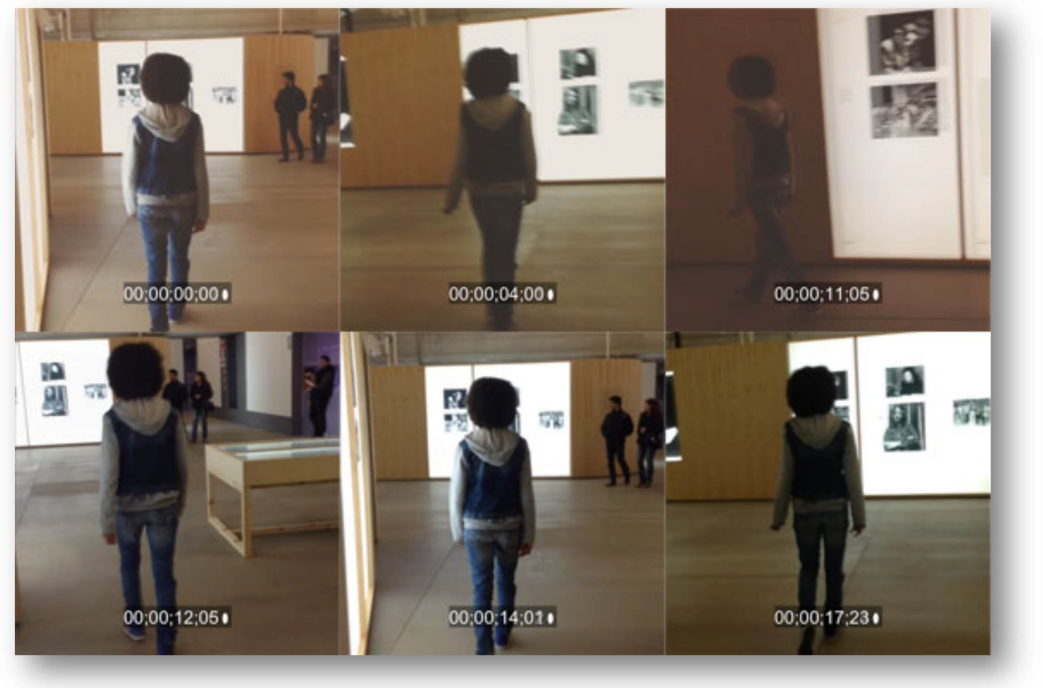

Image 7. Looping image. 20150118

Although the images do not stop repeating, as shown in image 7 , the participants manage to transmit a sense of continuity through the soundtrack used, although the limitations involved in editing this article do not allow the reader to hear this sound. Upon analysis of the productions made, we discovered that some participants were even able to build videos in which sound was the main driving force.

\section{c. Social networks and creative processes}

New media place people before broad audiences which need to be taken into account. Social relationships are often mediated by screens and in addition, sometimes there has never been in-person interaction. Users become content creators, who transmit their content through the network without having a clear awareness of who they are targeting. Today, it is essential to teach and learn not only the rules that allow for safe communication, but also how to transmit ideas based on who is watching or listening to us online.

\section{New multiplatform scenarios}

Reflective participation in the digital society was one of the goals of the workshops (Jenkins et al., 2015). The aim was to ensure that participants had full control and the ability to use social networks according to their own goals and to reflect on the reasons that underlie participation in these environments. This is demonstrated in the transcript below, in which the researcher enquires after the motivations of the participants:

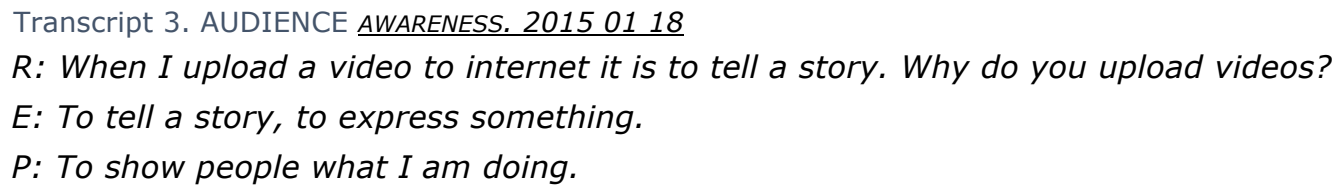

$R$ : When I upload a video to internet it is to tell a story. Why do you upload videos?

E: To tell a story, to express something.

P: To show people what I am doing.

That is, it is accepted that full participation in social networks depends not only on the ability to create content or communicate through them, but above all on the conscious use of what it means to interact with other people (Jenkins et al., 2015). At the point when participants were able to compare the activity they undertake on social networks with the social relationships they have in their physical environment, then they may have achieved reflective participation. 
The value of the message in individual and collective creations

Creativity is related to expressive and communicative acts which involve the reconstruction of reality. The Intermediae space, which houses artistic and scientific exhibitions, is extremely propitious to promote creativity in all its facets. Image 8 shows some of the girls in that environment.
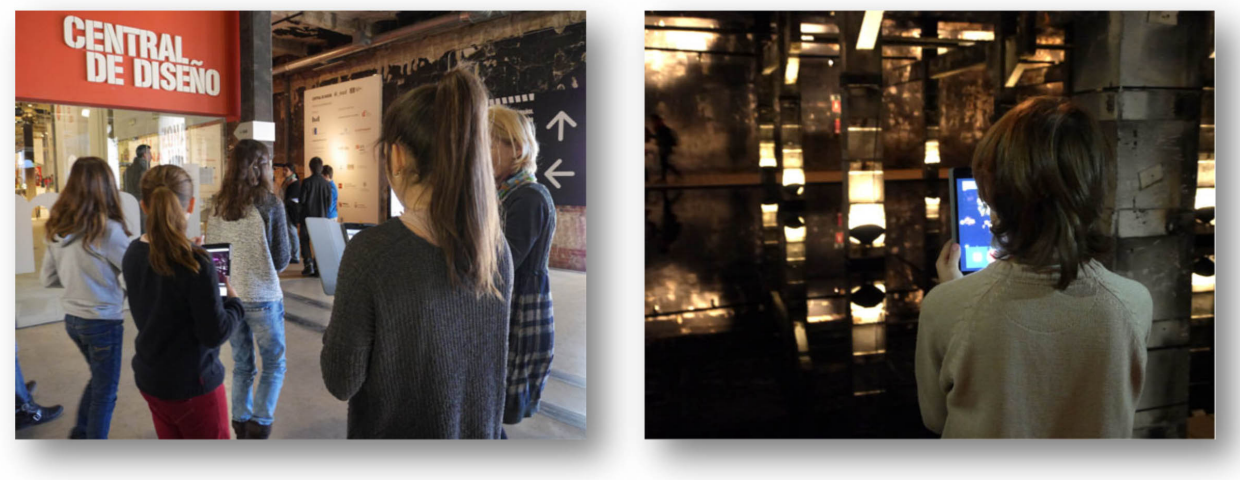

Image 8. Analyzing other works of art. 20180115

The young people were interested by the creative power of art right from the beginning. As reflected in the summaries of the research team, this was a first step which allowed us to subsequently address artistic creation in a more personal way:

Transcript 4. MATADERO SUMMARY M. 20150118

It was very interesting to see how children find it difficult to think of a theme to start recording. In spite of this, the chosen theme was art, so they searched for elements in the space that represented what art was for them.

Once the context has been established and the artistic reference points identified, the next step is to understand how the creation process takes place. At this point, we discovered that the use of models was a very useful reference point to enhance the participants' artistic expression. We showed them videos by various professionals and experts which were present in social networks, the platform on which they too would publish their creations. In addition, we realized that researchers need to create first, and make suggestions for participants to start creating for themselves. For example, the summary below shows how one of the youngest participants begins to create based on the instructions provided by a researcher:

Transcript 5. MATADERO SUMMARY S. 20150118

$R$. He is the youngest of all, and it is difficult for him to think about the message, which is why I challenged him to try and portray all the objects which are red. He thought this was a good idea and it became a guide for his work later in other videos. He manages to do another video about black things, and another about clothes, which he shows me and which is very beautiful.

The result is an audiovisual production that features all red objects. The participant found them at an exhibition that was taking place at the time in the "Central del Diseño", located at the Matadero. The main idea of the message is color, a notion which provides unity to the whole video. The production shows, sequence after sequence, images of different objects: a 
book, a lamp, paper shapes, etc. This will be the first of several videos that this child will make based on a common message in all the images, enhanced by the space itself and the objects present in it. The video was published on Vine.

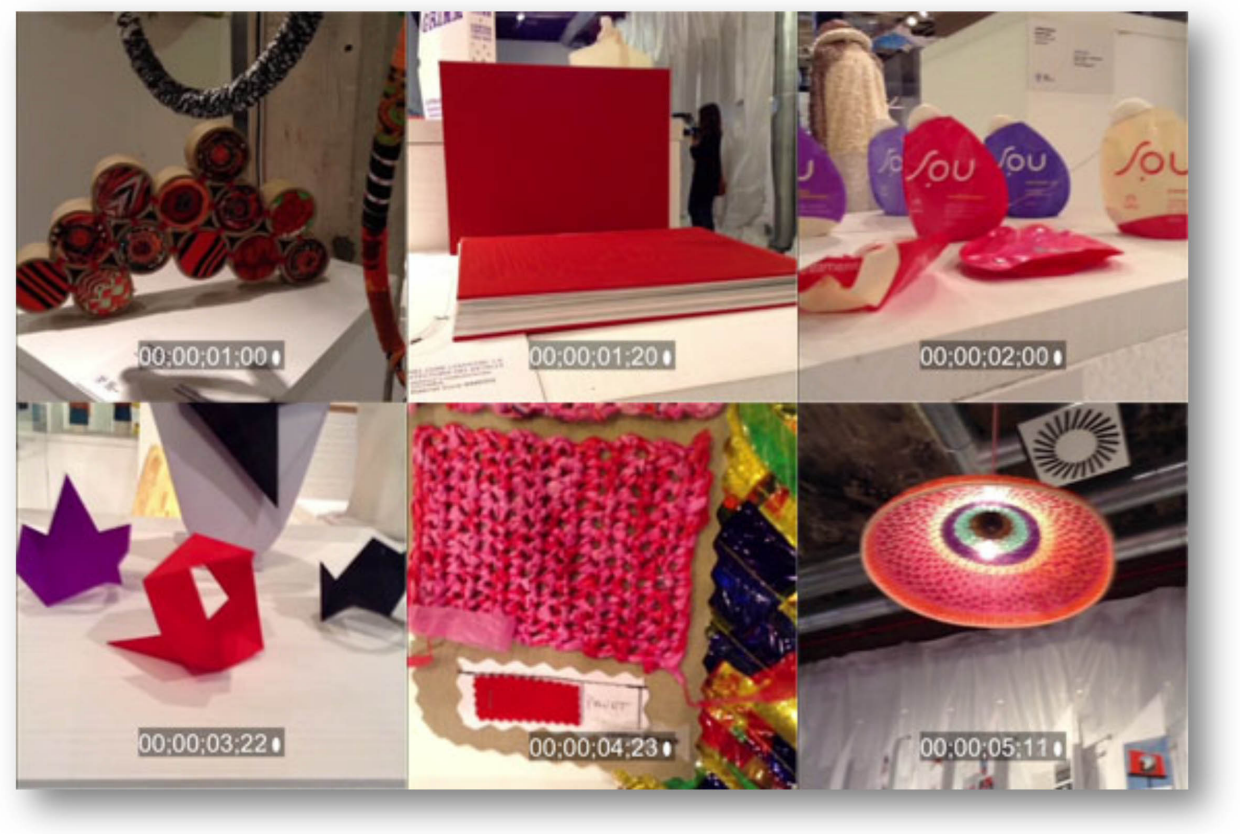

Image 9.The message from the red color. 20150208

Although art is the fruit of personal creation, the environment in which it is created and the activities carried out in a group have a considerable influence on the creation process. In addition to this, it is important to highlight that any child is able to create things if they have the appropriate reference points and models. Originality therefore depends on the ability to find a way to think of and look at things differently.

\section{Conclusion}

This study has shown how the creation of an innovative scenario, which introduces mobile devices like iPads in an environment such as the Matadero in Madrid, facilitates the use of multimodal discourses which in turn facilitate creative processes. In addition, personalized learning supported by young people's interest in social networks contributes to the development of digital literacies and transforms the activities of young people, who form part of a participatory culture.

The results of the analysis show how the open space of the community center was a determining factor in the act of creating. Matadero in Madrid provided a starting point for the thought process, because it provided an environment where participants could dialogue and share their opinions and experiences, supported by experts who are constantly changing and transforming their roles throughout the process and the session.

Dialogue in a large group between peers and researchers helped generate awareness of and reflection around the multimodal discourse used and of participation in social networks. In addition, conversations in physical and virtual environments allowed young people to establish a connection between real and virtual spaces. 
Moreover, our analysis of the various workshop sessions and our constant work with the young people contributed to an understanding of their creative processes, supported by people and cultural productions that served as a model. Knowledge and creation do not depend as much on the technical management of the physical equipment as on the use of criteria and on determining the suitability of one expressive resource or another, depending on the communicative needs that arise in certain physical or virtual contexts.

Finally, we will point out, finally, that the limitations of this study stem from the need to deepen new processes that help to understand how young people use multimodal discourses, which facilitate communication in online and offline scenarios, mediated by digital technology. For example, analyzing these processes in specific communities, in which young people participate spontaneously, would broaden the scope of this work. In short, the aim is to achieve greater internal validity of our data, which will allow us to expand and substantiate the achieved results.

\section{References}

Boellstorff, T. (2012). Ethnography and virtual worlds: a handbook of method. Princeton: Princeton University Press.

Buckingham, D. (2004). Educación en medios: alfabetización, aprendizaje y cultura contemporánea. Barcelona [etc]: Paidós.

Chomsky, N. (1965). Aspects of the theory of syntax. Cambridge, Massachusetts: MIT Press.

Coll, C. (2015). La personalización del aprendizaje escolar El qué, el por qué y el cómo de un reto insoslayable. En J. M. Vilalta (Ed.), Reptes de l'educació a Catalunya. Anuari d'Educació 2015 (Vol. Fundació Jaume Bofill. (Traducción de Iris Merino), pp. http://bit.ly/2HO41CP): Barcelona:

Denzin, N. K., \& Lincoln, Y. S. (2011). The SAGE handbook of qualitative research (4th ed.). Thousand Oaks, Calif.; London: Sage Publications.

Dominguez, S., \& Hollstein, B. (2014). Mixed methods social networks research: design and applications. Cambridge: Cambridge University Press.

Gee, J. P. (2003). What video games have to teach us about learning and literacy. New York: Palgrave Macmillan.

Gee, J. P. (2013). The anti-education era: creating smarter students through digital learning. New York, NY: The Palgrave McMillan.

Gee, J. P. (2014). An introduction to discourse analysis: theory and method (Fourth edition. ed.). New York: Routledge.

Guitart, M. E., \& Mendiburu, J. M. S. I. V. (2017). Informationalism and informalization of learnings in 21st century. A qualitative study on meaningful learning experiences. Historia Social y de la Educación, 6(1), 1-25.

Hartley, J. (2012). Digital futures for cultural and media studies. Malden: Wiley-Blackwell.

Jenkins, H., Clinton, K., Purushotma, R., Robison, A. J., \& Weigel, M. (2009). Confronting the ChaIIenges of Participatory Culture: Media Education for the 21 Century. MacArthur Foundation. Cambridge, MA: The MIT Press.

Jenkins, H., Ito-, M., \& Boyd, D. (2015). Participatory culture in a networked era: a conversation on youth, learning, commerce, and politics. Cambridge, UK; Malden, MA: Polity Press.

Jewitt, C. (2008). The visual in learning and creativity: a review of the literature. A report for Creative Partnerships. London: Arts Council.

Jones, R. H. (2012). Discourse and creativity (1st ed.). Harlow, England; New York: Pearson Longman.

Kemmis, S., McTaggart, R., \& Nixon, R. (2014). Introducing Critical Participatory Action Research. En S. Kemmis, R. McTaggart, \& R. Nixon (Eds.), The action research planner doing critical participatory action research (pp. 1-26). Singapore; London: Springer. 
Kress, G. R. (2010). Multimodality: a social semiotic approach to contemporary communication. London; New York: Routledge.

Kress, G. R., \& Van Leeuwen, T. (2001). Multimodal discourse: the modes and media of contemporary communication. London, New York: Arnold: Oxford University Press.

Lacasa, P., de-la-Fuente, J., \& Martín-Garrido, B. (Eds.). (2016). Youth Digital. Interactive Workshops. iBook http://apple.co/1RjtAsm. Madrid: iTunes: Apple Store (iBook).

Lacasa, P., Rut Martinez-Borda, \& Mendez, L. (2013). Media as Practice: Narrative and Conceptual Approach for Qualitative Data Analysis. Studies in Media and Communication. http://redfame.com/journal/index.php/smc/article/view/231, 1(1), 132-149.

Margolis, E., \& Pauwels, L. (2011). The SAGE handbook of visual research methods. Los Angeles: SAGE.

Negus, K., \& Pickering, M. (2004). Creativity, communication, and culture value. London; Thousand Oaks, Calif.: SAGE.

Penuel, W. R., \& O'Connor, K. (2018). From Designing to Organizing New Social Futures: Multiliteracies Pedagogies for Today. Theory into practice, 57(1), 64-71. doi: 10.1080/00405841.2017.1411715

Pink, S. (2012). Advances in visual methodology. London; Los Angeles: Sage Publications.

Stanczak, G. C. (2007). Visual research methods: image, society, and representation. Thousand Oaks, Calif.: Sage Publications.

Thurlow, C. (2012). Discourse Analysis and Languages and Linguistics. En R. H. Jones (Ed.), Discourse and creativity (1st ed., pp. 168-190). Harlow, England; New York: Pearson Longman.

Van-Dijk, T. A. (1997). Discourse as interaction in society. En T. A. van-Dijk (Ed.), Discourse as social interactions. (El discurso como interacción social. Barcelona: Gedisa, 2000) (Vol. 2, pp. 1-37). London: Sage.

Van-Dijk, T. A. (2014). Discourse and knowledge: A sociocognitive approach. New York: Cambridge University Press. 